Ambiente \& Água - An Interdisciplinary Journal of Applied Science
ISSN 1980-993X - doi:10.4136/1980-993X
www.ambi-agua.net
E-mail: ambi-agua@agro.unitau.br

\title{
Caracterização do perfil e da qualidade da experiência do praticante de rafting no Parque Estadual Serra do Mar - Núcleo Santa Virgínia
}

\author{
doi: 10.4136/ambi-agua.1257
}

Received: 16 Aug. 2013; Accepted: 22 Nov. 2013

\author{
Ana Paula Pereira ${ }^{1}$; Maria Dolores Alves Cocco ${ }^{1 *}$; Flávio José Nery Conde Malta ${ }^{1}$; \\ Maria de Jesus Robim² \\ ${ }^{1}$ Programa de Pós-Graduação em Ciências Ambientais (PPG-CA) \\ Universidade de Taubaté, Taubaté, SP, Brasil \\ ${ }^{2}$ Instituto Florestal, (IF) \\ Secretaria de Meio Ambiente do Estado de São Paulo, São Paulo, SP, Brasil \\ *Autor correspondente: e-mail: maria.cocco@unitau.br, \\ pereira.paula.geografia@gmail.com, flaviomalta@terra.com.br, mjesusrobim@gmail.com
}

\section{RESUMO}

O presente estudo visa subsidiar ações voltadas à implementação do rafting no Parque Estadual Serra do Mar - Núcleo Santa Virgínia (PESM-NSV). Teve como principal objetivo conhecer o perfil e o nível de satisfação dos praticantes de rafting no Núcleo Santa Virgínia. Para a coleta de dados foram utilizados questionários com perguntas fechadas e abertas, para identificação do perfil socioeconômico dos visitantes, informações sobre a viagem, motivações, preferências e nível de satisfação em relação às atividades desenvolvidas, bem como percepções sobre a experiência e mínimo impacto. Os dados foram analisados e tabulados e, posteriormente, realizou-se a análise de correspondência, para verificar a relação entre as variáveis 'satisfação' e 'idade', utilizando o aplicativo estatístico MINITAB. Dos 47 entrevistados, a maioria era do sexo masculino (66\%), sendo 55,5\% da faixa etária compreendida entre 19 e 30 anos, e $49 \%$ dos participantes do estudo possuíam nível superior completo. Em geral, os entrevistados apresentaram-se satisfeitos. Entretanto, ressaltaram alguns aspectos da gestão do rafting que poderiam ser melhorados, tais como diminuição de custos para realizar a atividade, e divulgação e melhoria da infraestrutura, principalmente, na área de desembarque no final do percurso. Conclui-se que os praticantes do rafting apresentam um perfil elitizado, com alta escolaridade, e demanda por serviços e produtos de qualidade.

Palavras-chave: rafting, unidade de conservação, satisfação do visitante, parque estadual da Serra do Mar.

\section{Characterization of the profile of rafting practitioners in the Serra do Mar State Park, Nucleus Santa Virginia, SP}

\begin{abstract}
This study aimed to provide support for the implementation of rafting in the Parque Estadual Serra do Mar - Núcleo Santa Virgínia (PESM-NSV) State Park based upon the profile and the level of satisfaction of the practitioners of rafting. Data was collected via questionnaires, with closed and open questions to assess the socioeconomic profile of the
\end{abstract}


practitioners, information regarding commuter trips, motivations, preferences, level of satisfaction with respect to the activities engaged in, as well as the practitioners' perceptions of the experience and minimum impact of the visits. After the data was tabulated, an Analysis of Correspondence technique was used to verify the relationship between the "satisfaction" and "age" variables using MINITAB ${ }^{\text {TM }}$ statistical software. Out of 47 people interviewed, the majority were males (66\%), of which $55.5 \%$ were between 19 and 30 years old and $49 \%$ of the participants had college degree. In general, participants were satisfied with the service, but made it clear that some aspects of the rafting business management could be improved upon, such as a reduction of the admission fee, use of availability announcements and improvement of the infrastructure of the landing area of the cruising. It is concluded that the rafting participants are from an elite class of society with a high level of education and a demand for a high quality of service.

Keywords: conservation, unit, radical sports, public use.

\section{INTRODUÇÃO}

As Unidades de Conservação são importantes estratégias para a conservação da biodiversidade dos biomas brasileiros. No Brasil, a Lei $n^{\circ}$. 9.985, de 18 de julho de 2000 (Brasil, 2000), regulamentou o Art. 225, $\S 1^{\circ}$, incisos I, II, III e VII da Constituição Federal, e criou o Sistema Nacional de Unidades de Conservação da Natureza, que estabeleceu critérios e normas para a criação, implantação e gestão das unidades.

Áreas ambientalmente protegidas têm por objetivo harmonizar a relação entre os mais variados ecossistemas e as sociedades humanas, fundamentalmente desenvolvendo equilíbrio entre ambas. No Brasil, o Sistema Nacional de Unidades de Conservação divide o conjunto das Unidades de Conservação em dois grupos, com características específicas: Unidades de Proteção Integral e Unidades de Uso Sustentável. Somente naquelas de proteção integral não é permitido o uso direto dos recursos, ou seja, a ação antrópica é restrita, sendo permitido apenas o uso indireto dos seus recursos naturais, com exceção dos casos previstos na Lei $n^{\circ}$. 9.985. A categoria dos parques, por exemplo, possibilita a realização de pesquisas científicas e o desenvolvimento de atividades de educação e interpretação ambiental, de recreação em contato com a natureza e de ecoturismo.

Áreas ambientalmente protegidas, principalmente as de proteção integral, desempenham importante papel para a conservação da biodiversidade e do bem-estar da sociedade. No entanto, a manutenção e a ampliação dessas áreas dependem da participação pública e de instrumentos educativos que propiciem novas percepções, valores e atitudes, a favor da conservação ambiental.

Atualmente, os Parques estão recebendo um número cada vez maior de visitantes, devido à busca por atividades de recreação e turismo de aventura (Swarbrooke, 2000). Para Krippendorf (2003), a necessidade de lazer demandada pelas sociedades pós-modernas constitui uma espécie de válvula de escape, uma fuga da rotina estressante (Körössy, 2008). O aumento da visitação, nessas áreas, cria a possibilidade de novos empregos, mas também desencadeia processos de degradação ambiental, como a destruição de importantes ecossistemas naturais. Dessa forma, faz-se fundamental e indispensável o planejamento adequado para atender às necessidades dos visitantes e também para garantir a conservação e os objetivos das áreas de proteção.

Segundo o Ministério do Turismo (Brasil, 2005), no Brasil o turismo de aventura teve suas primeiras iniciativas de atividades comerciais no início da década de 90. Ainda segundo esse autor, tal modalidade de turismo tem sido usada como ferramenta na educação ambiental, principalmente quando praticada em áreas de preservação ambiental. 
O mercado do turismo de aventura é promissor, mas as diversas empresas iniciam suas atividades sem qualquer controle sobre a qualidade dos serviços prestados (Schwartz e Carnicelli, 2006). O mesmo ocorre com as Unidades de Conservação que inserem o turismo de aventura nos seus atrativos e que enfrentam dificuldades, tanto pela falta de infraestrutura, quanto pela escassez de informações e pesquisas que avaliem os impactos causados pela visitação e pela qualidade da experiência do visitante.

A promoção e a afirmação dos valores e potencialidades que esses espaços encerram dependem do desenvolvimento de um processo de planejamento que concilie o uso recreativo e os objetivos de conservação dessas áreas. Os locais designados para as atividades de uso público devem ser manejados para controlar os efeitos negativos sobre o ambiente e garantir a qualidade da experiência do visitante (Frexêidas-Vieira et al., 2000).

No Plano de Manejo do Parque Estadual da Serra do Mar foi definido, como parte do Programa de Uso Público da unidade, o subprograma Visitação e Turismo Sustentável, cujos objetivos principais são: ordenar e monitorar a visitação para os diferentes tipos de público, contribuindo, assim, para a valorização do patrimônio natural e cultural do Parque, bem como para a sua conservação; formar uma consciência ambientalista por meio da vivência e interpretação do ambiente; promover oportunidades para o empreendedorismo e parcerias com instituições públicas, privadas e não governamentais, visando ao desenvolvimento local (São Paulo, 2006).

Segundo Villani et al. (2009), o Núcleo Santa Virgínia, um dos oito núcleos do Parque Estadual da Serra do Mar, possui belezas cênicas, rios e cachoeiras de grande atratividade aos visitantes que buscam realizar atividades de recreação, esporte e lazer ao ar livre e em contato direto com o meio ambiente preservado.

A Resolução SMA 59, de 27/08/2008, regulamenta os procedimentos administrativos de gestão e fiscalização do uso público das unidades de proteção integral do Sistema Estadual de Florestas do Estado de São Paulo - SIEFLOR e indica 10 princípios que regem o Programa nessas áreas, dentre eles: satisfação das expectativas dos visitantes no que diz respeito à qualidade e à variedade das experiências, da segurança e da necessidade de conhecimento.

De acordo com Villani et al.(2009), na proposta de regulamentação do Uso Público, a Fundação Florestal propôs ações estratégicas para regulamentar o rafting nas Unidades de Conservação sob sua gestão. Assim, entrou em vigor a Portaria Normativa 81/2008, de 18/12/2008, alterada pelas Portarias 150/2010, de 15/12/2010, e 153/2011, de 05/05/2011.

De outra parte, no âmbito do município de São Luís do Paraitinga, Estado de São Paulo, onde está localizada a sede do Núcleo Santa Virgínia, as atividades de rafting foram regulamentadas pela Lei Municipal $n^{\circ}$. 1.136, de 18/08/2004, com específica regulamentação município (Villani et al., 2009).

O Núcleo Santa Virgínia, no Parque Estadual da Serra do Mar, foi a primeira Unidade de Conservação paulista a regulamentar a atividade de turismo de aventura no Estado de São Paulo. Várias decisões normativas foram tomadas pelo órgão gestor, dentre elas a definição de limites para o número de usuários e a periodicidade da atividade. Com base nos estudos de capacidade de carga, a atividade não deve ser realizada nos dias úteis ou em todos os finais de semana. De acordo com os estudos desenvolvidos por Raimundo e Villani (2000), estima-se que as visitas sejam esporádicas, bem espaçadas da prática dos serviços de rafting ou atividades turísticas nos rios encontrados no território, para evitar impactos significativos à fauna.

Dessa forma, esta pesquisa teve como principal objetivo analisar o perfil e a qualidade da experiência dos praticantes de rafting no Núcleo Santa Virgínia. Isso para que, dessa maneira, os resultados subsidiem a Unidade de Conservação e as operadoras de rafting, na implementação de suas atividades, objetivando a valorização da experiência do visitante, bem 
como a criação de novos programas e atrativos, sempre pensando na conservação ambiental atrelada à recreação ao ar livre.

\section{MATERIAL E MÉTODOS}

\subsection{Entrevistas com os participantes do rafting}

Foram realizadas entrevistas todos os fins de semana, ao final de cada atividade, no período de 3 de abril de 2010 a 30 de maio de 2010, totalizando 86 usuários e 47 entrevistados, ou seja, uma amostragem de 54,5\%. Os participantes foram escolhidos aleatoriamente, de ambos os sexos, com idade a partir de 19 anos e independentemente do nível socioeconômico. Após o retorno dos questionários, os dados foram analisados, codificados e tabulados.

Inicialmente, realizou-se uma contagem das respostas sobre a avaliação da infraestrutura e dos serviços oferecidos pelo PESM - NSV e operadoras de rafting, assim como sobre a percepção dos turistas quanto à disponibilidade e grau de satisfação em relação aos recursos oferecidos pelo Núcleo Santa Virgínia.

Ao final da classificação dos dados, foi utilizada a técnica desenvolvida pelos franceses, Análise de Correspondência, conhecida por converter uma matriz de dados não negativos em um tipo particular de gráfico em que as linhas e colunas são representadas simultaneamente em dimensão reduzida, por pontos, para verificar a equivalência entre as variáveis que, nesta pesquisa, são o grau de 'satisfação' e a 'idade' (Czermainski, 2004). Para tanto, utilizou-se o software estatístico MINITAB, versão 15. Para realizar essa análise pelo aplicativo, inicialmente copiaram-se os dados para o worksheet: uma coluna apresentava as idades, e a outra, a avaliação da satisfação. Uma terceira coluna apresentava as faixas-etárias (19 a 30 anos, 31 a 40 anos, 41 a 50 anos e mais de 51 anos) e uma quarta coluna, as categorias referentes à satisfação (ruim, aceitável, boa e excelente).

No entanto, a faixa etária com mais de 51 anos só teve um participante, e a categoria de satisfação ruim não foi selecionada por nenhum entrevistado. Tendo em vista essa inexpressividade, a faixa etária de mais de 51 anos e o nível de satisfação ruim foram retirados da Análise de Correspondência.

A coluna que continha as faixas-etárias e a coluna com as categorias referentes à satisfação foram especificadas, para que o programa pudesse realizar o cruzamento das informações. O comando que realizou a análise foi Stat > Multivariate > Simple Correspondence Analyses.

Feita a operação, gerou-se a tabela de contingência com I (linhas) por J (colunas), que continham as quantidades das informações. Essa tabela ofereceu uma classificação cruzada da faixa etária dos entrevistados ( $\mathrm{I}=3$ categorias) e opinião dos entrevistados quanto à satisfação com a visitação ( $\mathrm{J}=3$ categorias). No entanto, o principal produto gerado, com a técnica de Análise de Correspondência, foi o gráfico de ordenação da satisfação X faixa-etária, o qual contém as coordenadas dos pontos plotados e a medida da quantidade de informação (inércia) retida em cada dimensão.

Segundo Lúcio et al. (1999), a Análise de Correspondência é um método para determinação de um sistema de associação entre os elementos de dois ou mais conjuntos, buscando explicar a estrutura de associação dos fatores em questão. Dessa forma, são construídos gráficos com os componentes principais das linhas e das colunas, permitindo a visualização da relação entre os conjuntos, em que a proximidade dos pontos referentes à linha e à coluna indica associação, e o distanciamento, uma repulsão.

Para Mingoti (2005), os métodos da estatística multivariada são utilizados com o objetivo de simplificar ou facilitar a interpretação do fenômeno que está sendo estudado, por meio da 
construção de índices ou variáveis alternativas que sintetizem a informação original dos dados.

Uma das grandes vantagens de se trabalhar com a Análise de Correspondência, de acordo com Czermainski (2004), é que essa técnica permite revelar relações que não teriam sido percebidas se a análise fosse feita aos pares de variáveis. Além disso, ela é altamente flexível, no tratamento dos dados, por não ser necessária a adoção de nenhum modelo teórico de distribuição de probabilidade, basta que se tenha uma matriz retangular, contendo dados não negativos.

\section{RESULTADOS E DISCUSSÃO}

\subsection{Caracterização, perfil e satisfação dos participantes do rafting}

Primeiramente foi caracterizado o perfil socioeconômico dos turistas do rafting no Parque Estadual Serra do Mar - Núcleo Santa Virgínia.

Dos 47 participantes entrevistados, a maioria é do sexo masculino, o equivalente a $66 \%$, sendo $34 \%$ do sexo feminino (Tabela 1 ).

Tabela 1. Sexo dos participantes do rafting PESM - NSV.

\begin{tabular}{cc}
\hline Sexo & Quantidade \\
\hline Masculino & 31 \\
Feminino & 16 \\
\hline
\end{tabular}

$\mathrm{Na}$ Tabela 2, fica evidente que 55,5\% dos entrevistados se encontram na faixa etária de 19 a 30 anos, $32 \%$ de 31 a 40 anos, 10,5\% na faixa de idade de 41 a 50 anos e apenas $2 \%$ com mais de 51 anos.

Tabela 2. Faixa etária dos participantes do rafting PESM NSV.

\begin{tabular}{cc}
\hline Faixa etária & Quantidade \\
\hline 19 a 30 anos & 26 \\
31 a 40 anos & 15 \\
41 a 50 anos & 5 \\
> 51 anos & 1 \\
\hline
\end{tabular}

A maioria dos turistas entrevistados, $47 \%$, é da capital do Estado de São Paulo. São do vale do Paraíba, 25,5\%; da região da Grande São Paulo, 15\%; de outros Estados, 10,5\%; e, do Litoral Norte, $2 \%$. Outro resultado que caracteriza a população entrevistada é que $89,5 \%$ dos visitantes são residentes do Estado de São Paulo e que apenas 10,5\% vivem em outros Estados, como Rio de Janeiro e Pernambuco. Esses dados estão apresentados na Tabela 3.

Não foi observado fluxo de turistas estrangeiros, no rafting PESM - NSV, no período da coleta de dados, o que caracteriza essa região como um destino de turismo doméstico.

Dos entrevistados, $42,5 \%$ têm nível superior incompleto, $25,5 \%$ têm pós-graduação, $23,5 \%$ têm superior completo, e 8,5\%, ensino médio. Nenhum participante tem apenas o ensino fundamental. Esses dados demonstram o alto nível de escolaridade dos praticantes dessa modalidade de turismo de aventura, pois, somando os que possuem nível superior completo e os pós-graduados, tem-se 49\%. (Tabela 4). 
Tabela 3. Origem dos participantes do rafting PESM - NSV.

\begin{tabular}{lcc}
\hline Cidade onde mora & Estado onde mora & Quantidade \\
\hline São Paulo & SP & 22 \\
São J.dos Campos & SP & 7 \\
Rio de Janeiro & RJ & 4 \\
Taubaté & SP & 2 \\
Mogi das Cruzes & SP & 2 \\
Osasco & SP & 2 \\
Jambeiro & SP & 2 \\
São Bernardo & SP & 1 \\
Mauá & SP & 1 \\
Caçapava & SP & 1 \\
Ubatuba & SP & 1 \\
Guarulhos & SP & 1 \\
Recife & PE & 1 \\
\hline
\end{tabular}

Tabela 4. Grau de instrução dos participantes do rafting PESM - NSV.

\begin{tabular}{lc}
\hline Grau de instrução & Quantidade \\
\hline Fundamental & 0 \\
Médio & 4 \\
Superior Incompleto & 20 \\
Superior Completo & 11 \\
Pós-graduação & 12 \\
\hline
\end{tabular}

Não houve prevalência de uma ocupação específica, sendo a mais citada a de Engenheiro (Tabela 5).

Tabela 5. Ocupação dos participantes do rafting PESM - NSV.

\begin{tabular}{lc}
\hline Ocupação & Quantidade \\
\hline Engenheiro & 12 \\
Estudante & 4 \\
Estagiário & 3 \\
Professor & 3 \\
Técnico & 3 \\
Bancário & 2 \\
Enfermeiro & 2 \\
Eletricista & 2 \\
Representante & 2 \\
Almoxarife & 1 \\
Publicitário & 1 \\
Médico veterinário & 1 \\
Designer gráfico & 1 \\
Administrador & 1 \\
Aeroportuário & 1 \\
Comerciário & 1 \\
Empresário & 1 \\
Desenvolvedor de Sistema & 1 \\
Coordenador técnico & 1 \\
Analista de suporte & 1 \\
Musicista & 1 \\
Biólogo & 1 \\
Vendedor & 1 \\
Agente de turismo & 1 \\
\hline
\end{tabular}


Em seguida, foram levantadas as informações sobre a viagem, frequência das visitas, motivações, preferências dos usuários em relação às atividades desenvolvidas e percepções sobre mínimo impacto.

Dos turistas de aventura que participaram da pesquisa, 79\% estavam visitando o PESM NSV pela primeira vez, e os $21 \%$ restantes frequentam a Unidade de Conservação até três vezes ao ano. Essas informações são importantes para o melhor planejamento e divulgação de atividades relacionadas à conduta de mínimo impacto e de interpretação e educação ambiental que são oferecidas aos visitantes, tanto pelas operadoras de rafting, quanto pelo Núcleo Santa Virgínia, de forma a garantir que os praticantes da atividade de aventura não causem impactos significativos ao Parque e que tal atividade possa ser usada como ferramenta para a conservação ambiental. Observam-se esses dados na Tabela 6.

Tabela 6. Frequência de visita ao PESM - NSV.

\begin{tabular}{lc}
\hline $\begin{array}{l}\text { Frequência de visita ao } \\
\text { PESM - NSV }\end{array}$ & Quantidade \\
\hline Primeira vez & 37 \\
Até 3 vezes ao ano & 10 \\
De 4 a 10 vezes ao ano & 0 \\
Mais de 10 vezes ao ano & 0 \\
\hline
\end{tabular}

Dos entrevistados, $83 \%$ visitam o PESM - NSV e realizam o rafting junto com os amigos, principalmente colegas de trabalho, $10,5 \%$ com companheiro (a) e uma pequena porcentagem, 6,5\% com a família. (Tabela 7).

Tabela 7. Com quem visita o PESM NSV.

\begin{tabular}{lc}
\hline Com quem visita o & Quantidade \\
PESM - NSV & 0 \\
\hline Sozinho & 3 \\
Família & 39 \\
Amigos & 5 \\
Companheiro (a) & 0 \\
Grupo de excursão & \\
\hline
\end{tabular}

Na questão referente à frequência de prática do rafting, houve um empate nas alternativas de primeira vez e de até três vezes ao ano $44,5 \%$. As opções de quatro a dez vezes e de mais duas vezes ao ano apresentaram $8,5 \%$ e, $5 \%$, respectivamente (Tabela 8 ).

Tabela 8. Frequência com que pratica o rafting.

\begin{tabular}{lc}
\hline $\begin{array}{l}\text { Frequência com que } \\
\text { pratica o } \text { rafting }\end{array}$ & Quantidade \\
\hline Primeira vez & 21 \\
Até 3 vezes ao ano & 21 \\
De 4 a 10 vezes ao ano & 4 \\
Mais de 10 vezes ao ano & 1 \\
\hline
\end{tabular}

Quando analisados os dados sobre realização do rafting em outras cidades, teve-se $51 \%$ de respostas positivas contra 49\% negativas (Tabela 9). 
Tabela 9. Realização de rafting pelos entrevistados que já o praticaram em outras cidades.

\begin{tabular}{cc}
\hline $\begin{array}{c}\text { Realização de rafting } \\
\text { em outras cidades }\end{array}$ & Quantidade \\
\hline Sim & 24 \\
Não & 23 \\
\hline
\end{tabular}

Dentre os lugares mais citados de realização do rafting foram apontados: Socorro, Brotas, Juquitiba e Extrema, e até mesmo outros países, como Eslovênia, Panamá e Peru (Tabela 10).

Tabela 10. Cidade ou país em que os entrevistados já praticaram rafting.

\begin{tabular}{cc}
\hline Cidade ou país em que já realizaram rafting & Quantidade \\
\hline Socorro & 12 \\
Brotas & 8 \\
Juquitiba & 7 \\
Extrema & 2 \\
Jalapão & 1 \\
Itajaí do Sul & 1 \\
Três Rios & 1 \\
Pelotas & 1 \\
Eslovênia & 1 \\
Panamá & 1 \\
Peru & 1 \\
\hline
\end{tabular}

$\mathrm{Na}$ Tabela 11, observou-se que uma parcela significativa dos entrevistados apontou como motivo para a escolha do rafting o lazer. Apareceram também as opções contato com a natureza e novas emoções. Nessa questão, foi permitida a escolha de mais de uma opção.

Tabela 11. Motivações para a escolha do rafting.

\begin{tabular}{lc}
\hline & Quantidade \\
\hline Contato com a natureza & 22 \\
Já pratica esse esporte & 4 \\
Lazer & 24 \\
Novas emoções & 21 \\
Outros & 4 \\
\hline
\end{tabular}

A Tabela 12 indica que os amigos representam a principal fonte de divulgação, seguida da Internet. Verifica-se a necessidade de se incentivar outras estratégias, ou até mesmo de aperfeiçoar a ferramenta tecnológica, para possibilitar a veiculação de uma variedade de informações sobre os objetivos de conservação e as características e condutas de mínimo impacto para a realização das atividades do rafting no Núcleo Santa Virgínia. Também, nessa questão, foi permitido apontar mais de uma opção. 
Tabela 12. Fontes de informações sobre o rafting PESM NSV.

\begin{tabular}{lc}
\hline $\begin{array}{c}\text { Como descobriu informações sobre o } \\
\text { rafting - NSV }\end{array}$ & Quantidade \\
\hline Internet & 6 \\
Amigos & 36 \\
Revistas ou manuais de turismo & 0 \\
Agências de turismo & 3 \\
Outros & 3 \\
\hline
\end{tabular}

Na questão sobre a experiência do rafting, foi permitida a escolha de mais de uma opção. A satisfação do turista que pratica o rafting no Parque Estadual Serra do Mar - Núcleo Santa Virgínia, no geral é elevada, o que pode ser evidenciado pelos altos valores na classificação da experiência do rafting, nas alternativas: marcante, inesquecível e satisfatória (Tabela 13).

Tabela 13. Classificação da experiência do rafting no PESM - NSV.

\begin{tabular}{cc}
\hline $\begin{array}{c}\text { O rafting PESM - NSV foi } \\
\text { uma experiência }\end{array}$ & Quantidade \\
\hline Comum & 0 \\
Previsível & 0 \\
Satisfatória & 7 \\
Marcante & 23 \\
Inesquecível & 19 \\
\hline
\end{tabular}

A intenção de retorno ao rafting no Parque Estadual da Serra do Mar foi apontada por 98\% dos entrevistados (Tabela 14).

Tabela 14. Retorno ao rafting no PESM - NSV.

\begin{tabular}{cc}
\hline $\begin{array}{c}\text { Praticaria rafting novamente no } \\
\text { PESM - NSV }\end{array}$ & Quantidade \\
\hline Sim & 46 \\
Não & 1 \\
\hline
\end{tabular}

A maioria dos turistas mostrou-se satisfeita em relação à infraestrutura e serviços, no PESM - NSV. Esse resultado fica evidente no alto número de respostas boa e excelente para: limpeza e estado de conservação da infraestrutura da Unidade de Conservação, $21,5 \%$ e 72,5\%; segurança contra acidentes, $30 \%$ e 66\%; qualidade das informações, $53 \%$ e 42,5\%; quantidade das informações, 55,5\% e 36\%; monitores, $34 \%$ e $62 \%$; e, recepção e atendimento, $47 \%$ e $34 \%$. Já os itens gastos com a atividade e divulgação tiveram expressiva percentagem em respostas aceitáveis, mas sempre superada pelas respostas boas, como demonstra a Tabela 15. 
Tabela 15. Avaliação de infraestrutura e serviços oferecidos pelo PESM - NSV e operadoras de rafting.

\begin{tabular}{lcccc}
\hline Características & Ruim & Aceitável & Boa & Excelente \\
\hline Limpeza e estado de conservação da infraestrutura do & 1 & 2 & 10 & 34 \\
PESM-NSV & 2 & 11 & 27 & 7 \\
Gastos com a atividade & 0 & 2 & 14 & 31 \\
Segurança contra acidentes & 1 & 1 & 25 & 20 \\
Qualidade das informações & 2 & 2 & 26 & 17 \\
Quantidade de informações & 2 & 0 & 16 & 29 \\
Monitores & 3 & 6 & 22 & 16 \\
Recepção e atendimento & 2 & 12 & 29 & 4 \\
Divulgação & & & & \\
\hline
\end{tabular}

Novamente, a maioria dos turistas mostrou-se satisfeita, ao apontar respostas excelentes e boas em relação aos recursos naturais $(42,5 \%$ e 38,5\%), estruturas do PESM - NSV (68\% e $23 \%)$, trilha do rafting (53,5\% e 36\%), limpeza da área (74,5\% e $21,5 \%)$, infraestrutura e serviços $(42,5 \%$ e $42,5 \%)$, e número de visitantes (53\% e 40,5\%). No item sobre a influência dos recursos oferecidos pelo PESM - NSV na visita, aparecem informações contraditórias, como um alto índice nas opções nada e muito, que podem ser explicados pelo fato de muitos entrevistados entenderem que certas características, como a excelente limpeza, influenciaram muito o passeio, de maneira positiva. Tais dados estão apresentados na Tabela 16.

Tabela 16. Análise da percepção dos turistas quanto à disponibilidade e grau de satisfação dos recursos oferecidos pelo PESM - NSV.

\begin{tabular}{|c|c|c|c|c|}
\hline \multirow{3}{*}{$\begin{array}{l}\text { Características } \\
\text { Danos aos recursos naturais }\end{array}$} & \multicolumn{2}{|c|}{ Situação que você viu } & \multicolumn{2}{|c|}{ Como influenciou sua visita } \\
\hline & 1 ruim & 18 boa & 14 nada & 9 médio \\
\hline & 8 aceitável & 20 excelente & 9 pouco & 15 muito \\
\hline \multirow{2}{*}{ Danos às estruturas } & 0 ruim & 11 boa & 23 nada & 9 médio \\
\hline & 4 aceitável & 32 excelente & 5 pouco & 10 muito \\
\hline \multirow{2}{*}{ Trilha do rafting } & 0 ruim & 17 boa & 18 nada & 6 médio \\
\hline & 5 aceitável & 25 excelente & 6 pouco & 17 muito \\
\hline \multirow{2}{*}{ Limpeza } & 0 ruim & 10 boa & 18 nada & 6 médio \\
\hline & 2 aceitável & 35 excelente & 2 pouco & 21 muito \\
\hline \multirow{2}{*}{ Infraestrutura e serviços } & 0 ruim & 20 boa & 17 nada & 10 médio \\
\hline & 7 aceitável & 20 excelente & 4 pouco & 16 muito \\
\hline \multirow{2}{*}{ Número de visitantes } & 0 ruim & 19 boa & 20 nada & 7 médio \\
\hline & 3 aceitável & 25 excelente & 3 pouco & 17 muito \\
\hline
\end{tabular}

O grau de satisfação dos entrevistados, segundo os aspectos de infraestrutura, econômicos, administrativos e logísticos resultou na classificação de cada indivíduo (Tabela 17). 
Tabela 17. Satisfação dos visitantes ao PESM - NSV.

\begin{tabular}{|c|c|c|c|c|c|}
\hline Individuo & $\begin{array}{l}\text { Faixa } \\
\text { etária }\end{array}$ & $\begin{array}{c}\text { Grau de } \\
\text { Satisfação }\end{array}$ & Individuo & Faixa etária & $\begin{array}{c}\text { Grau de } \\
\text { Satisfação }\end{array}$ \\
\hline 1 & 19 a 30 & boa & 25 & 19 a 30 & boa \\
\hline 2 & 19 a 30 & boa & 26 & 19 a 30 & excelente \\
\hline 3 & 41 a 50 & boa & 27 & 19 a 30 & excelente \\
\hline 4 & 31 a 40 & boa & 28 & 19 a 30 & aceitável \\
\hline 5 & 19 a 30 & boa & 29 & 19 a 30 & boa \\
\hline 6 & 31 a 40 & excelente & 30 & 19 a 30 & boa \\
\hline 7 & 31 a 40 & excelente & 31 & 19 a 30 & boa \\
\hline 8 & 19 a 30 & boa & 32 & 19 a 30 & boa \\
\hline 9 & 31 a 40 & excelente & 33 & 19 a 30 & aceitável \\
\hline 10 & 31 a 40 & boa & 34 & 19 a 30 & excelente \\
\hline 11 & 31 a 40 & excelente & 35 & 19 a 30 & boa \\
\hline 12 & 31 a 40 & excelente & 36 & 19 a 30 & boa \\
\hline 13 & 31 a 40 & excelente & 37 & 19 a 30 & excelente \\
\hline 14 & 31 a 40 & boa & 38 & 19 a 30 & excelente \\
\hline 15 & 31 a 40 & excelente & 39 & 19 a 30 & excelente \\
\hline 16 & $>51$ & excelente & 40 & 19 a 30 & aceitável \\
\hline 17 & 31 a 40 & excelente & 41 & 19 a 30 & excelente \\
\hline 18 & 41 a 50 & excelente & 42 & 19 a 30 & boa \\
\hline 19 & 41 a 50 & excelente & 43 & 41 a 50 & excelente \\
\hline 20 & 19 a 30 & excelente & 44 & 31 a 40 & excelente \\
\hline 21 & 19 a 30 & excelente & 45 & 31 a 40 & excelente \\
\hline 22 & 41 a 50 & excelente & 46 & 31 a 40 & boa \\
\hline 23 & 19 a 30 & boa & 47 & 31 a 40 & excelente \\
\hline 24 & 19 a 30 & boa & & & \\
\hline
\end{tabular}

Da Tabela 17 gerou-se a tabela de contingência (Tabela 18), com a classificação cruzada da faixa etária dos entrevistados $(\mathrm{I}=3$ categorias $)$ e a opinião deles quanto à satisfação com a visitação ( $\mathrm{J}=3$ categorias).

Tabela 18. Tabela de contingência do nível de satisfação por faixa-etária.

\begin{tabular}{ccccc}
\hline Faixa etária & Aceitável & Boa & Excelente & Total \\
\hline 19 a 30 & 3,000 & 14,000 & 9,000 & 26,000 \\
31 a 40 & 0,000 & 4,000 & 11,000 & 15,000 \\
41 a 50 & 0,000 & 1,000 & 4,000 & 5,000 \\
Total & 3,000 & 19,000 & 24,000 & 46,000 \\
\hline
\end{tabular}

A partir da tabela de contingência, foi calculado o Qui-quadrado, dado por:

$$
\chi^{2}=\sum_{i=1} \frac{\left(O_{i}-E_{i}\right)^{2}}{E_{i}}
$$

em que:

$E_{i}$ é a frequência esperada e $\left(\mathrm{O}_{\mathrm{i}}-\mathrm{E}_{\mathrm{i}}\right)$ é a frequência observada menos a frequência esperada. Esse procedimento avaliou a associação existente entre as variáveis satisfação e idade. As frequências esperadas são: (Tabela 19). 
Tabela 19. Frequência esperada calculada a partir da frequência observada.

\begin{tabular}{cccc}
\hline Faixa etária & Aceitável & Boa & Excelente \\
\hline 19 a 30 & 1,696 & 10,739 & 13,565 \\
31 a 40 & 0,978 & 6,196 & 7,826 \\
41 a 50 & 0,326 & 2,065 & 2,609 \\
\hline
\end{tabular}

E as diferenças entre as frequências observadas e esperadas são: (Tabela 20)

Tabela 20. Frequência observada menos frequência esperada.

\begin{tabular}{cccc}
\hline Faixa etária & Aceitável & Boa & Excelente \\
\hline 19 a 30 & 1,304 & 3,261 & $-4,565$ \\
31 a 40 & $-0,978$ & $-2,196$ & 3,174 \\
41 a 50 & $-0,326$ & $-1,065$ & 1,391 \\
\hline
\end{tabular}

As distâncias Qui-quadrado calculadas estão apresentadas na Tabela 21.

Tabela 21. Distância Qui-quadrado.

\begin{tabular}{ccccc}
\hline Faixa etária & Aceitável & Boa & Excelente & Total \\
\hline 19 a 30 & 1,003 & 0,990 & 1,536 & 3,530 \\
31 a 40 & 0,978 & 0,778 & 1,287 & 3,044 \\
41 a 50 & 0,326 & 0,549 & 0,742 & 1,618 \\
Total & 2,308 & 2,318 & 3,566 & 8,191 \\
\hline
\end{tabular}

A estatística Qui-quadrado (que é dada pelo somatório) corresponde ao valor total de 8.19. Para a Análise de Correspondência entre as linhas (faixa-etária) e colunas (satisfação), avaliou- se a proporção de opinião para cada faixa-etária, que é dada pela tabela do perfil da linha (Tabela 22), e a distribuição de faixa-etária para cada opinião, verificando-se a tabela do perfil da coluna (Tabela 23).

Tabela 22. Perfil de linha: proporção de opinião por faixa-etária.

\begin{tabular}{cccc}
\hline Faixa etária & Aceitável & Boa & Excelente \\
\hline 19 a 30 & 0,115 & 0,538 & 0,346 \\
31 a 40 & 0,000 & 0,267 & 0,733 \\
41 a 50 & 0,000 & 0,200 & 0,800 \\
Mass & 0,065 & 0,413 & 0,522 \\
\hline
\end{tabular}

Tabela 23. Perfil de coluna: distribuição de faixa-etária por opinião.

\begin{tabular}{cccc}
\hline Faixa etária & Aceitável & Boa & Excelente \\
\hline 19 a 30 & 1,000 & 0,737 & 0,375 \\
31 a 40 & 0,000 & 0,211 & 0,458 \\
41 a 50 & 0,000 & 0,053 & 0,167 \\
Mass & 0,065 & 0,413 & 0,522 \\
\hline
\end{tabular}

No entanto, o principal produto da análise de correspondência foi o gráfico de ordenação, que apresenta as coordenadas dos pontos plotados e a medida da quantidade de informação (inércia) retida em cada dimensão. A figura de ordenação da satisfação $\mathrm{X}$ faixa-etária está apresentada na Figura 1. 


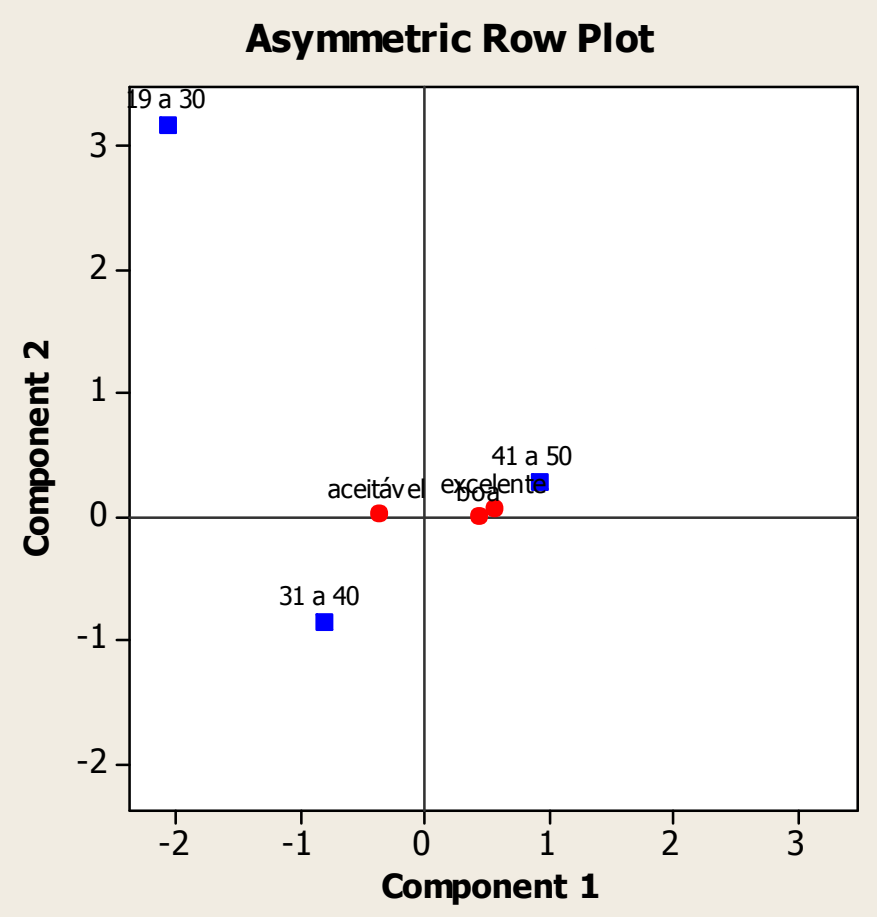

Figura 1. Distribuição de pontos por satisfação: em vermelho, a indicação do grau de satisfação (do aceitável ao excelente) e em azul, o intervalo de faixa-etária.

A Figura 1 demonstra que os entrevistados na faixa-etária de 41 a 50 anos tiveram uma opinião definida sobre a prática do rafting, dentro do excelente e bom, conforme o indicado na cor verde.

O inverso foi observado na faixa-etária de 19 a 30 anos que, apesar de representar o maior número de praticantes da atividade de aventura, não definiu uma classe de satisfação. Já a faixa-etária intermediária (31 a 40 anos) não se mostrou satisfeita com a atividade, pois estava mais próxima do aceitável.

\section{CONCLUSÃO}

As áreas protegidas destinadas à conservação da biodiversidade também podem ser consideradas polos de atração regional e de desenvolvimento local, se estimuladas à visitação pública, compatibilizando, o turismo e a conservação da natureza. Assim, o turismo sustentável nessas regiões, desde que planejado adequadamente, propiciará benefícios às comunidades locais gerando novas oportunidades de negócios e emprego, tornando-se uma relevante ferramenta de educação ambiental.

Destaca-se, neste estudo, a importância de se conhecer o perfil e a percepção dos turistas que visitam o Parque Estadual Serra do Mar - Núcleo Santa Virgínia para praticar o rafting, modalidade de turismo de aventura, de forma a propiciar maior integração desses aspectos, no planejamento da Unidade de Conservação. Consequentemente, será possível garantir uma experiência rica e agradável aos visitantes, sem que eles causem impactos significativos e para que contribuam com a proteção da área.

Sendo assim, chega-se à conclusão de que os praticantes do rafting apresentam um perfil elitizado, com alta escolaridade, o que gera uma demanda por serviços e produtos diferenciados.

Essa atividade tem atraído um público mais jovem, na faixa de 19 a 40 anos, que em sua maioria visita pela primeira vez o PESM - NSV. O visitante vem acompanhado de amigos. 
Observa-se, também, que grande parte é do sexo masculino, que reside no Estado de São Paulo e que busca contato com a natureza e novas formas de lazer.

O resultado das análises indicou que a faixa etária de 41 a 50 anos tende a achar mais satisfatória a atividade, em comparação com visitantes de outras faixas etárias. Em geral, os entrevistados apresentaram-se satisfeitos, mas alguns aspectos podem ser melhorados para garantir satisfação plena dos turistas, tais como os gastos com a atividade, a divulgação e a infraestrutura, principalmente no final da atividade.

\section{REFERÊNCIAS}

BRASIL. Lei Federal n. ${ }^{0}$ 9.985, de 18 de julho de 2000. Disponível em: <http://www.planalto.gov.br/ccivil_03/leis/19985.htm>.. Acesso em: dez. 2010.

BRASIL. Ministério do Turismo. Regulamentação, normalização e certificação em turismo de aventura: relatório diagnóstico. Brasília, 2005. 85p.

CZERMAINSKI, A. B. Análise de correspondência. Piracicaba, [s.n.], 2004. Disponível em: 〈http://ce.esalq.usp.br/tadeu/anabeatriz.pdf>. Acesso em: set. 2011.

FREIXÊDAS-VIEIRA, V. M.; PASSOLD, A. J.; MAGRO, T. C. Impactos do uso público: um guia de campo para utilização do Método VIM. In: CONGRESSO BRASILEIRO DE UNIDADES DE CONSERVAÇÃO, 2., 2000, Campo Grande. Anais... Campo Grande: Rede Nacional Pró Unidade de Conservação; Fundação O Boticário de Proteção à Natureza, 2000. p. 296-306.

KOROSSY, N. Do "turismo predatório" ao "turismo sustentável": uma revisão sobre a origem e a consolidação do discurso da sustentabilidade na atividade turística. Caderno Virtual de Turismo, v. 8, n. 2, p. 56-68, 2008.

KRIPPENDORF, J. Sociologia do turismo: para uma nova compreensão do lazer e das viagens. 3. ed. São Paulo: Aleph, 2003. 184p.

LUCIO, P. S.; TOSCANO, E. M. M.; ABREU, M. L. Caracterização de séries climatológicas pontuais via análise canônica de correspondência - estudo de caso. Revista Brasileira de Geofísica, v.17, p. 41, 1999.

MINGOTI, S. A. Análise de dados através de métodos de estatística multivariada: uma abordagem aplicada. Belo Horizonte: Editora UFMG, 2005.

RAIMUNDO, S.; VILLANI, J. P. Estudo de capacidade de carga e proposta de regulamentação do rafting no Núcleo Santa Virgínia - Parque Estadual da Serra do Mar (SP). In: CONGRESSO BRASILEIRO DE UNIDADES DE CONSERVAÇÃO, 2. 2000, Campo Grande. Anais... Campo Grande: [s.n.], 2000. p. 232-242.

SÃO PAULO (Estado). Secretaria do Meio Ambiente. Instituto Florestal. Parque estadual da Serra do Mar - plano de manejo. São Paulo, 2006 . 441p.

SCHWARTZ, G. M.; CARNICELLI FILHO, S. (Desin)formação profissional e atividade de aventura: focando os guias de "rafting". Revista Brasileira Educação Física e Esporte, São Paulo, v. 20, n. 2, p. 103-109, abr./jun. 2006.

SWARBROOKE, J. Turismo sustentável: conceitos e impacto ambiental. São Paulo: Aleph, 2000. 410p. v.1. 
VILLANI, J. P. et al. Caminos para la implementación del rafting en una unidad de conservación del bioma mata atlántica, São Paulo, Brasil. In: CONVENCIÓN DEL MÉDIO AMBIENTE Y DESARROLLO, 7.; CONGRESO DE ÁREAS PROTEGIDAS, 6., 2009, Havana. Anais... Havana: Ministerio de Ciencia, Tecnología y Medio Ambiente de la República de Cuba, 2009. p.191-203. 